\title{
Design of a Production Process for Poly(oxymethylene) Dimethyl Ethers from Dimethyl Ether and Trioxane
}

Christian F. Breitkreuz ${ }^{1}$, Niklas Schmitz ${ }^{1}$, Eckhard Ströfer ${ }^{1}$, Jakob Burger ${ }^{1, *}$, Hans Hasse ${ }^{1}$

\begin{abstract}
Poly(oxymethylene) dimethyl ethers (OME) are promising synthetic fuels. When compared to fossil diesel fuel, OME reduce the soot formation in diesel engines. OME can be produced from the $\mathrm{C} 1$ platform syngas via different routes. This work investigates an OME production process via dimethyl ether and trioxane. The process is simulated and optimized using process simulation with varying model depth. As no experimental data are available on the chemical equilibrium of the reaction of dimethyl ether and trioxane, chemical equilibrium constants are partly estimated from formation data of the reactants.
\end{abstract}

\section{Keywords}

Poly(oxymethylene) dimethyl ethers, Process design, dimethyl ether, synthetic fuel

\section{Introduction}

Poly(oxymethylene) dimethyl ethers (OME) are oligomers with the chemical structure $\mathrm{CH}_{3}-\mathrm{O}$ $\left(\mathrm{CH}_{2}-\mathrm{O}\right)_{n}-\mathrm{CH}_{3}, n \geq 2$, where $n$ is the number of formaldehyde repetition units. OME are promising synthetic diesel fuels. When used as fuels, OME with $n=3-5$ are most desirable [1-3]. Thy physical properties of OME of such chain lengths are similar to fossil diesel fuel, therefore, only slight modifications of engines are required [1-3]. When burned in

\footnotetext{
${ }^{1}$ M.Sc. Christian Frederik Breitkreuz, M.Sc. Niklas Schmitz, Prof. Dr.-Ing. Jakob Burger, Dipl.-Chem.

* Corresponding author; Present address: Chair for Chemical Process Engineering, Technical University of Munich, Schulgasse 16, 94315 Straubing, Germany, burger@tum.de
} 
combustion engines, they show low soot emissions. Indirectly the emissions of nitrogen oxides are reduced as well [4].

OME can in principle be produced from synthesis gas via the intermediate methanol and dimethyl ether [5]. Synthesis gas can be produced from renewable as well as fossil resources [6, 7]. Especially the use of metallurgical gases from steel production as source for synthesis gas is interesting [8]. This would represent an ecological efficient coupling of two big branches of industry to minimize the emission of carbon dioxide. While the production of methanol and dimethyl ether from synthesis gas is possible with state-of-the-art technologies [7], routes from methanol and dimethyl ether to OME are still being discussed $[9,10]$. An overview of different routes from syngas to OME is given in Fig. 1. For all routes, the final OME synthesis step requires two reactants: a) one reactant providing methyl end groups of $\mathrm{OME}$, like dimethyl ether (DME), methylal, or methanol and b) one reactant providing the $\mathrm{CH}_{2} \mathrm{O}$ units of $\mathrm{OME}$, like aqueous or methanolic formaldehyde solution, trioxane, or paraformaldehyde. [11, 12]

\section{Here Figure 1}

There are some works on Route A [12, 14-16]. Schmitz et al. [14] describe a production process using aqueous solutions of formaldehyde and methanol. Mixtures of formaldehyde, water and methanol are complex reacting mixtures, as oligomers of formaldehyde both with water and methanol are formed. Because of the azeotropic behavior of the mixtures, the work up of the reactor outlet is more complicated. In addition, the presence of water lowers the yields of OME in the reactor, because of the competing oligomerization reactions [17]. Water is not only part of the feed mixture, but it is also formed in the reaction of formaldehyde with methanol to OME. Despite these challenges, Schmitz et al. [14] were able to design a remarkably simple process for Route $A$, that only contains a fixed-bed reactor, two distillation columns and an adsorption or membrane unit for the separation of water. 
Route $B$, in which OME are produced from trioxane and methylal, was examined by several groups [2, 18-25]. Most works focus on the reactor and catalyst design. Only Burger et al. $[2,22,23]$ investigate the whole process. A process with a fixed-bed reactor and two distillation columns was designed. As water and methanol are not present in Route $\mathrm{B}$, the downstream processing of the reactor outlet is simplified compared to Route A. Methylal can be seen as an OME with $n=1$. Weidert et al. [26] describe a process for producing methylal from formaldehyde and methanol. Trioxane is a cyclic trimer of formaldehyde. Grützner et al. [27] describe a process for producing trioxane from an aqueous formaldehyde solution.

A promising alternative is the use of dimethyl ether instead of methylal (Route C). Dimethyl ether is cheaper than methylal. It is produced either from methanol or directly from synthesis gas [28]. It is also discussed as platform molecule, that can be obtained from carboncontaining metallurgical gases from steel production $[8,29]$. Dimethyl ether can be regarded as an OME of chain length $n=0$. Haltenort et al. [30] have recently demonstrated the feasibility of the acid-catalyzed reaction of dimethylether and trioxane into OME. Quantitative experimental data on the equilibrium of the reaction is, however, presently not available. In the patent literature, however, Ströfer et al. [31] describe a process for the production of OME from dimethyl ether and trioxane. The work-up of the reactor outlet is similar to that of Route B.

In the present work, the process of Ströfer et al. [31] is evaluated in detail to provide a basis for the assessment of Route C. A simulation-based design and optimization of the process was carried out using two process models of different model depth.

\section{Process concept}

A flowsheet of the OME production process from dimethyl ether and trioxane, as described by Ströfer et al. [31], is shown in Fig. 2. 
Here Figure 2

A stream of dimethyl ether and trioxane (stream 1) is mixed with two recycle streams 4 and 6. This mixed stream 2 enters the reactor containing a heterogeneous acidic catalyst. The reactor outlet (stream 3) enters the distillation column C1. This column separates dimethyl ether, methylal, $\mathrm{OME}_{2}$, formaldehyde, and trioxane as overhead product (stream 4), from the OME of chain length $n \geq 3$. In the distillation column C2 stream 5 is separated into the product fraction of OME with $n=3-5$ (stream 7) and the heavy-boiling fraction of OME with $n \geq 6$ (stream 6). Stream 4 and stream 6 are recycled back to the reactor. This is possible, because all reactions in the present system are reversible, see Sect. 2.1.

\section{Chemical model}

\subsection{Chemical reactions}

Trioxane $\left(\mathrm{TRX},\left(\mathrm{CH}_{2} \mathrm{O}\right)_{3}\right)$ is cleaved to formaldehyde $\left(\mathrm{FA}, \mathrm{CH}_{2} \mathrm{O}\right)$ according to Reaction (1). Formaldehyde reacts with dimethyl ether to methylal (MAL), c.f. Reaction (2). Longer OME are formed by further insertion of formaldehyde into the chain, c.f. Reaction (3) for methylal and Reaction (4) for OME of general chain length $n \geq 2$.

$$
\begin{aligned}
\mathrm{TRX} & \stackrel{\mathrm{H}^{+}}{\rightleftharpoons} 3 \mathrm{FA} \\
\mathrm{DME}+\mathrm{FA} & \stackrel{\mathrm{H}^{+}}{\rightleftharpoons} \mathrm{MAL} \\
\mathrm{MAL}+\mathrm{FA} & \stackrel{\mathrm{H}^{+}}{\rightleftharpoons} \mathrm{OME}_{2} \\
\mathrm{OME}_{n}+\mathrm{FA} & \stackrel{\mathrm{H}^{+}}{\rightleftharpoons} \mathrm{OME}_{n+1}
\end{aligned}
$$

Reactions (5) to (7) describe an alternative mechanism of the chain growth by direct reaction of OME with trioxane. Since in this work, only the chemical equilibrium and not the kinetics 
are considered, it is irrelevant for the calculations which of the two mechanisms are assumed. All reactions are catalyzed by acids and are reversible equilibrium reactions.

$$
\begin{aligned}
& \mathrm{DME}+\frac{1}{3} \mathrm{TRX} \stackrel{\mathrm{H}^{+}}{\rightleftharpoons} \mathrm{MAL} \\
& \mathrm{MAL}+\frac{1}{3} \mathrm{TRX} \rightleftharpoons \mathrm{H}^{+} \rightleftharpoons \mathrm{OME}_{2} \\
& \mathrm{OME}_{n}+\frac{1}{3} \mathrm{TRX} \rightleftharpoons \mathrm{H}^{+} \rightleftharpoons \mathrm{OME}_{n+1}
\end{aligned}
$$

\subsection{Chemical equilibrium constants}

The equilibrium is modeled with equilibrium constants $K_{j}$ based on mole fractions $\left(x^{n}\right)$, c.f. Eqs. (8) to (14). Therein, the subscript $j$ denotes the reaction number.

$$
\begin{aligned}
& K_{1}=\frac{x_{\mathrm{FA}}^{\mathrm{n}}{ }^{3}}{x_{\mathrm{TRX}}^{\mathrm{n}}} \\
& K_{2}=\frac{x_{\mathrm{MAL}}^{\mathrm{n}}}{x_{\mathrm{DME}}^{\mathrm{n}} \cdot x_{\mathrm{FA}}^{\mathrm{n}}} \\
& K_{3}=\frac{x_{\mathrm{OME}_{2}}^{\mathrm{n}}}{x_{\mathrm{MAL}}^{\mathrm{n}} \cdot x_{\mathrm{FA}}^{\mathrm{n}}} \\
& K_{4}=\frac{x_{\mathrm{OME}_{\mathrm{n}+1}}^{\mathrm{n}}}{x_{\mathrm{OME}}^{\mathrm{n}} \cdot x_{\mathrm{FA}}^{\mathrm{n}}} \\
& K_{5}=\frac{x_{\mathrm{MAL}}^{\mathrm{n}}}{x_{\mathrm{DME}}^{\mathrm{n}} \cdot x_{\mathrm{TRX}}^{\mathrm{n}} \mathrm{x}^{\frac{1}{3}}} \\
& K_{6}=\frac{x_{\mathrm{MEE}_{2}}^{\mathrm{n}}}{x_{\mathrm{MAL}}^{\mathrm{n}} \cdot x_{\mathrm{TRX}}^{\mathrm{n}} x^{\frac{1}{3}}} \\
& K_{7}=\frac{x_{O M E_{n+1}}^{n}}{x_{O M E_{n}}^{n} \cdot x_{T R x^{n}}^{\frac{1}{3}}}
\end{aligned}
$$

The equilibrium constants for Reactions (3) and (4), respectively Reactions (6) and (7) are simplified in literature to one constant $[12,22]$. The temperature dependency of the chemical equilibrium constant is described by Eq. (15). 


$$
\ln \left(K_{j}\right)=a_{j}+\frac{b_{j}}{(T / K)}
$$

The Reactions (5) to (7) are linear dependent on the Reactions (1) to (4). In this work, Reactions (1) to (4) are used for the description of the chemical equilibrium in the reactor. The equilibrium constant $K_{1}$ is reported by Burger et al. [22]. Therein, the constant $K_{1}$ is only given with high uncertainty because of the difficult measurement of monomeric formaldehyde concentration. Therefore, the literature value of $K_{1}$ is not used in the present work. The constant $K_{2}$ is not reported in the literature. The constants $K_{3}$ and $K_{4}$ are reported by Schmitz et al. [12] and adopted in the present work. The constants $K_{1}$ and $K_{2}$ are calculated from three other constants via Eqs. (16) and (17).

$$
\begin{aligned}
& K_{1}=\left(\frac{K_{7}}{K_{4}}\right)^{3} \\
& K_{2}=\frac{K_{5}}{K_{1}{ }^{\frac{1}{3}}}
\end{aligned}
$$

Eq. (16) is obtained by dividing Eq. (14) by Eq. (11) to the power of three and comparing with Eq. (8). Eq. (17) is obtained by dividing Eq. (12) by Eq. (8) to the power of one third and comparing with Eq. (9). The constants $K_{6}$ and $K_{7}$ are reported by Burger et al. [22] and adopted in the present work. The missing constant $K_{5}$ is estimated from the Gibbs energy of formation of dimethyl ether, trioxane and methylal using the data for the standard state presented in Tab. 1 and the data for heat capacities in Tab. 2. The pressure dependency of the enthalpy and entropy is neglected as a liquid phase reaction is studied. Constant $K_{5}$ is calculated for various temperatures in the range $298.15-353.15 \mathrm{~K}$. The results are regressed with Eq. (15). The calculation is described in detail in the Supporting Information. A comparison of the estimated constant $K_{2}$ with the constant for the OME formation $K_{3}$ is shown in Fig. 3. It can be seen that the constant $K_{2}$ is smaller than $K_{3}$ and is slightly more temperature sensitive. This indicates that the equilibrium of reaction (2) might be more on the educt side than the equilibrium of reaction (3). This should be validated by experiments in 
future work. The reaction enthalpy for the formation of methylal from dimethyl ether and formaldehyde is $18.25 \mathrm{~kJ} \mathrm{~mol}^{-1}$. This is slightly less than the reaction enthalpy of reaction (3) and (4).

Here Figure 3

Here Table 1

Here Table 2

The parameters $a_{j}$ and $b_{j}$ for the calculation of the chemical equilibrium constants are given for all reactions in Tab. 3.

Here Table 3

\section{Physical property model}

\subsection{Pure component properties}

The pure component properties required for the simulation are the vapor pressure, the enthalpy of vaporization, the ideal gas heat capacity at constant pressure, and the liquid molar density. The correlations for the pure component properties, except for dimethyl ether, are taken from Burger et al [23]. The correlations for dimethyl ether are taken from DIPPR [32].

\subsection{Vapor-liquid equilibrium}

The vapor-liquid equilibrium in the system (formaldehyde + trioxane + dimethyl ether + $\left.\mathrm{OME}_{n}\right)$ is calculated with the extended Raoult's law. For the description of the non-ideality in the liquid phase a UNIFAC-based model is used as described by Schmitz et al. [33]. These authors did, however, not consider dimethyl ether and trioxane. Albert et al. [34] modeled trioxane as one structural group in the UNIFAC model. The volume- and surface-parameters of that group and its interaction parameters with the group formaldehyde are adopted from Albert et al. [34]. The interaction-parameters with the groups describing methylal and $\mathrm{OME}_{n}$ 
are set to zero. Further, dimethyl ether is also modeled as one structural group in the present work. The volume- and surface-parameters are adopted from Sundberg et al. [35]. The interaction parameters of the dimethyl ether group are set equal to those of methylal. The interaction-parameters between methylal and dimethyl ether are set to zero. All values are given in Tab. S1 and S2 in the Supporting information.

\section{Process design}

\subsection{Implementation}

The physical-property model was implemented into the equation-oriented flowsheet simulation tool CHEMASIM, an in-house tool of BASF. The distillation columns are simulated using the equilibrium-stage model. The process design is carried out using process simulation and optimization with two models of varying model depth. This hierarchical design method is adopted from the work of Burger et al. [36]. The two different process models are described in the following.

\section{$4.2 \infty / \infty$ model of the process}

For the reactor it is assumed, that chemical equilibrium is reached. The two columns $\mathrm{C} 1$ and C2 are assumed to have an infinite number of stages $(N)$ and an infinite reflux ratio $(R)$. This enables sharp separations only constrained by distillation boundaries and mass balances [37]. In the system of the present work, there are no distillation boundaries and the top and bottom products can be gained in arbitrary purity as long as the boiling sequence is considered.

\subsection{Design with an $\infty / \infty$ model}

Due to the simplifying assumptions of the $\infty / \infty$ model, only five design parameters need to be specified. The reactor temperature is set to $353.15 \mathrm{~K}$. It is expected that at this temperature the formation of side products, such as methyl formate, is suppressed [22]. Further, the influence of the temperature on the compositions in chemical equilibrium is small $[12,22]$. 
Because all results scale linearly with the mass flow of the feed stream, it is set arbitrarily to $10 \mathrm{~kg} \mathrm{~s}^{-1}$. The distillate-to-feed ratios of the columns C1 and C2 are specified with the sharp separation described above in the process concept.

The only degree of freedom left is the mass fraction of dimethyl ether $x_{\mathrm{DME}}$ in the feed stream. The $\infty / \infty$ model gives no information on the energy demand and the size of the equipment of the OME process. Therefore, here the mass flows of the recycle streams 4 and 6 are defined as objectives to be minimized. These two flows are conflicting objectives. By varying the mass fraction of dimethyl ether in the feed stream, the Pareto front representing the set of best compromises, is calculated. On the Pareto front, a decrease in one recycle mass flow can only be achieved by an increase of the other recycle mass flow. More details on Pareto optimization and its application to process engineering are given in the work of Bortz et al. [38]. The Pareto front is shown in Fig. 4.

Here Figure 4

Fig. 4 contains also an operating point. It is assumed to be a good compromise between the two goals in which the objective of minimizing the overhead recycle stream is prioritized. The corresponding mass fraction of dimethyl ether in the feed stream is $0.283 \mathrm{~g} \mathrm{~g}^{-1}$ and was fixed for the subsequent optimization of the OME process using a more detailed process model.

\subsection{Detailed process model}

The reduced model gives no information on properties such as the heat duties $(\dot{Q})$, reflux ratios or stage numbers. To obtain this information, the process is modeled in more detail. As no information on the kinetics of the chemical reactions in the present system is available, the reactor outlet is still assumed to be in the chemical equilibrium. The temperature of the feed stream is set to $335.15 \mathrm{~K}$, the melting temperature of trioxane, to have a liquid stream. In the detailed process model, the distillation columns have finite number of stages and reflux ratios. For each distillation column the following design parameters have to be specified in the simulations: columns pressure, number of stages in rectifying and stripping section, and 
two further specifications (e.g. purities or reflux ratio). The design procedure to set these specifications is described in the following.

\subsection{Design with detailed model}

The pressure of column $\mathrm{C} 1$ is specified such that the condenser temperature is $313 \mathrm{~K}$. At this temperature cooling water can be used throughout the year. The pressure of column C2 is set to 50 mbar to minimize thermal OME decomposition in the bottom. Lower pressures were not used to avoid a further increase of the volumetric flow rate of the gas in the column. One specification per column is given by the product specifications, which were adopted from the work of Burger et al. [23]: In the product stream 7, the sum of the mass fractions of OME with $n \leq 2$ and trioxane is set to $0.0005 \mathrm{~g} \mathrm{~g}^{-1}$ and the sum of the mass fractions of OME with chain length $n \geq 6$ is set to $0.0095 \mathrm{~g} \mathrm{~g}^{-1}$. Furthermore the recycle ratios of $\mathrm{OME}_{3}$ and that of $\mathrm{OME}_{5}$ are used as design parameters. The recycle ratio of $\mathrm{OME}_{3}$ is defined as the ratio between the component mass flow of $\mathrm{OME}_{3}$ in stream 4 and the component mass flow of $\mathrm{OME}_{3}$ in the feed of column C1 (stream 3) $\left(\dot{m}_{\mathrm{OME}_{3}, 4} / \dot{m}_{\mathrm{OME}_{3}, 3}\right)$. The recycle ratio of $\mathrm{OME}_{5}$ is defined as the component mass flow of $\mathrm{OME}_{5}$ in stream 6 divided by the component mass flow of $\mathrm{OME}_{5}$ in stream $5\left(\dot{m}_{\mathrm{OME}_{5,6}} / \dot{m}_{\mathrm{OME}_{5}, 5}\right)$. Both ratios as well as the stage numbers of the columns are used as optimization parameters. These four optimization parameters are varied to minimize the sum of heat duties in the reboilers of the columns. For the optimization the following strategy was selected:

1. The process was simulated with $N=30$ for both columns and the feed stages were set on stage 15 (counting from the bottom).

2. The recycle ratios of $\mathrm{OME}_{3}$ and $\mathrm{OME}_{5}$ were simultaneously optimized to minimize the sum of the reboiler duties of both columns.

3. A N,Q-study as described by Zeck [39] was performed for columns $\mathrm{C} 1$ and $\mathrm{C} 2$. The resulting $N, \dot{Q}$-curves are presented in Figure 5 . The number of stages corresponding to 1.2 times the minimum reboiler duty, with two additional stages as safety margin, 
was selected as design for the columns. The optimal feed stages were taken from the $N, \dot{Q}$-study.

\section{Here Figure 5}

4. Step 2 was repeated.

Further iterations showed no significant changes of the results. The specifications of the process are given in Tab.4. The resulting parameters of the columns $\mathrm{C} 1$ and $\mathrm{C} 2$ are presented in Tab. 5. A stream table of the whole process is presented in Tab. 6.

Here Table 4

Here Table 5

Here Table 6

\section{Discussion}

The results obtained with the detailed process model show that the reboiler duty of column $\mathrm{C} 1$ is about 15 times that of column $\mathrm{C} 2$, although the heat duty of the condenser is nearly the same. This is caused by the large pressure difference between the two columns. The feed stream of column C2 is overheated and only little additional energy is needed. The total heat requirement per $\mathrm{kg}$ product is $1870 \mathrm{~kJ} \mathrm{~kg}^{-1}$, which is $40 \%$ higher than the number reported by Burger et al. [23] for Route B with the same product specifications. This is mainly caused by the large amount of dimethyl ether that has to be recycled in the present process. The number of stages of the columns is similar in both processes. The higher energy costs of the present process may be compensated as dimethyl ether is cheaper than methylal.

The above results should be used with caution. They are based on an estimation of the chemical equilibrium of the methylal formation from dimethyl ether. The simulation results are quite sensitive to the value of that equilibrium constant: e.g. an increase of the equilibrium constant $K_{2}$ by $12.7 \%$ decreases the size of both recycle streams by $15.2 \%$. Since estimated and measured equilibrium constants often deviate significantly, it is necessary to 
investigate the chemical equilibrium constants in experiments before reliable statements about investment and energy cost of the process can be obtained. These experiments are topic of ongoing work in our group.

\section{Conclusion}

This work presents a closed material and energy balance of the OME production process from trioxane and dimethyl ether. Based on thermodynamic estimations of unknown chemical equilibrium constants, the OME production process described by Ströfer et al. [31] was simulated and optimized. The results show that this synthesis route can be an interesting alternative to the OME production from methylal and trioxane, which is conceptually similar to the process simulated in the present work. The energy demand for this process is higher than for the methylal process, but the reactant dimethyl ether is cheaper than methylal. The chemical equilibrium constant of the formation of methylal from dimethyl ether and trioxane was estimated here from the free energies of the pure components in the standard state. As the process performance depends strongly on these equilibrium constants, experimental studies are needed.

\section{Acknowledgments}

Das diesem Bericht zugrundeliegende Vorhaben Carbon2Chem ${ }^{\circledR}$ wurde mit Mitteln des Bundesministeriums für Bildung, und Forschung unter dem Förderkennzeichen 03EK3043E gefördert. Die Verantwortung für den Inhalt dieser Veröffentlichung liegt beim Autor.

\section{Symbols used}

\section{Symbols}

$\begin{array}{lll}a & {[-]} & \text { correlation parameter } \\ A & {[-]} & \text { correlation parameter } \\ b & {[-]} & \text { correlation parameter } \\ B & {[-]} & \text { correlation parameter } \\ c_{p} & {\left[\mathrm{~kJ} \mathrm{~mol}^{-1} \mathrm{~K}^{-1}\right]} & \text { molar heat capacity of } \\ & & \text { component } \mathrm{i}\end{array}$




$\begin{array}{lll}C & {[-]} & \text { correlation parameter } \\ h & {\left[\mathrm{~kJ} \mathrm{~mol}^{-1}\right]} & \text { enthalpy } \\ i & {[-]} & \text { component } \\ K & {\left[\mathrm{~mol} \mathrm{~mol}^{-1}\right]} & \text { molar equilibrium constant } \\ \dot{m} & {\left[\mathrm{~kg} \mathrm{~s}^{-1}\right]} & \text { mass flow } \\ n & {[-]} & \text { oligomer chain length } \\ N & {[-]} & \text { number of theoretical stages of } \\ & & \text { a distillation column } \\ p & {\left[\mathrm{bar}^{-1}\right.} & \text { pressure } \\ \dot{R} & {\left[\mathrm{~kJ} \mathrm{~s}^{-1}\right]} & \text { heat duties } \\ R & {[-]} & \text { reflux ratio } \\ s & {\left[\mathrm{~kJ} \mathrm{~K}^{-1} \mathrm{~mol}^{-1}\right]} & \text { molar entropy } \\ T & {\left[\mathrm{~K}^{-1}\right.} & \text { temperature } \\ x & {\left[\mathrm{~g} \mathrm{~g}^{-1}\right]} & \text { mass fraction } \\ x^{n} & {\left[\mathrm{~mol} \mathrm{~mol}^{-1}\right]} & \text { mole fraction }\end{array}$

\section{Greek symbols}

$\theta$

[-]

reference condition

\section{Sub- and Superscripts}

$\begin{array}{ll}\text { cond } & \text { condenser } \\ \text { feed } & \text { feed } \\ \text { fus } & \text { fusion } \\ i & \text { component } \\ j & \text { number of reaction } \\ \text { liq } & \text { liquid phase } \\ \text { reb } & \text { reboiler } \\ \text { vap } & \text { vapor phase }\end{array}$

\section{Abbrevations}

DME

FA

MAL

OME

$\operatorname{TRX}$ dimethyl ether

formaldehyde

methylal

poly(oxymethylene) dimethyl ethers

trioxane 


\section{References}

[1] B. Lumpp, D. Rothe, C. Pastötter, R. Lämmermann, E. Jacob, MTZ Worldw 2011, 72 (3), 34 - 38. DOI: 10.1365/s38313-011-0027-z.

[2] J. Burger, M. Siegert, E. Ströfer, H. Hasse, Fuel 2010, 89 (11), 3315 - 3319. DOI: 10.1016/j.fuel.2010.05.014.

[3] S. Schemme, R. C. Samsun, R. Peters, D. Stolten, Fuel 2017, 205, 198 - 221. DOI: 10.1016/j.fuel.2017.05.061.

[4] M. Härtl, K. Gaukel, D. Pélerin, G. Wachtmeister, MTZ Motortech Z 2017, 78 (2), 52 59. DOI: 10.1007/s35146-016-0170-9.

[5] X. Zhang, A. O. Oyedun, A. Kumar, D. Oestreich, U. Arnold, J. Sauer, Biomass and Bioenergy 2016, 90, 7 - 14. DOI: 10.1016/j.biombioe.2016.03.032.

[6] R. L. Pruett, Science (New York, N.Y.) 1981, 211 (4477), 11 - 16. DOI: 10.1126/science.211.4477.11.

[7] G. A. Olah, A. Goeppert, G. K. S. Prakash, Beyond Oil and Gas: The Methanol Economy, 2nd ed., Wiley, Somerset 2011.

[8] M. Oles, W. Lüke, R. Kleinschmidt, K. Büker, H.-J. Weddige, P. Schmöle, R. Achatz, Chemie Ingenieur Technik 2018, 90 (1-2), 169 - 178. DOI: 10.1002/cite.201700112.

[9] N. Schmitz, J. Burger, E. Ströfer, H. Hasse, Fuel 2016, 185, 67 - 72. DOI: 10.1016/j.fuel.2016.07.085.

[10] B. Niethammer, S. Wodarz, M. Betz, P. Haltenort, D. Oestreich, K. Hackbarth, U. Arnold, T. Otto, J. Sauer, Chemie Ingenieur Technik 2018, 90 (1-2), 99 - 112. DOI: $10.1002 /$ cite.201700117.

[11] D. Oestreich, L. Lautenschütz, U. Arnold, J. Sauer, Fuel 2018, 214, 39 - 44. DOI: 10.1016/j.fuel.2017.10.116.

[12] N. Schmitz, F. Homberg, J. Berje, J. Burger, H. Hasse, Ind. Eng. Chem. Res. 2015, 54 (25), 6409 - 6417. DOI: 10.1021/acs.iecr.5b01148.

[13] J. Burger, A novel process for the production of diesel fuel additives by hierarchical design, Scientific report series / Technische Universität Kaiserslautern, Laboratory of Engineering Thermodynamics, vol. 3, Tech. Univ., Laboratory of Engineering Thermodynamics, Kaiserslautern 2012.

[14] N. Schmitz, E. Ströfer, J. Burger, H. Hasse, Ind. Eng. Chem. Res. 2017, 56 (40), 11519 - 11530. DOI: 10.1021/acs.iecr.7b02314.

[15] D. Oestreich, L. Lautenschütz, U. Arnold, J. Sauer, Chemical Engineering Science 2017, 163, 92 - 104. DOI: 10.1016/j.ces.2016.12.037.

[16] J. Zhang, D. Fang, D. Liu, Ind. Eng. Chem. Res. 2014, 53 (35), 13589 - 13597. DOI: 10.1021/ie501231a.

[17] I. Hahnenstein, H. Hasse, C. G. Kreiter, G. Maurer, Ind. Eng. Chem. Res. 1994, 33 (4), 1022 - 1029. DOI: $10.1021 / \mathrm{ie00028a033.}$

[18] L. Lautenschütz, D. Oestreich, P. Haltenort, U. Arnold, E. Dinjus, J. Sauer, Fuel Processing Technology 2017, 165, 27 - 33. DOI: 10.1016/j.fuproc.2017.05.005.

[19] H. Li, H. Song, F. Zhao, L. Chen, C. Xia, Journal of Energy Chemistry 2015, 24 (2), 239 - 244. DOI: 10.1016/S2095-4956(15)60307-2.

[20] Q. Wu, W. Li, M. Wang, Y. Hao, T. Chu, J. Shang, H. Li, Y. Zhao, Q. Jiao, RSC Adv 2015, 5 (71), 57968 - 57974. DOI: 10.1039/C5RA08360E. 
[21] L. Lautenschütz, Neue Erkenntnisse in der Syntheseoptimierung oligomerer Oxymethylendimethylether aus Dimethoxymethan und Trioxan, Ph.D. Thesis, Heidelberg University 2015.

[22] J. Burger, E. Ströfer, H. Hasse, Ind. Eng. Chem. Res. 2012, 51 (39), 12751 - 12761. DOI: 10.1021/ie301490q.

[23] J. Burger, E. Ströfer, H. Hasse, Chemical Engineering Research and Design 2013, 91 (12), 2648 - 2662. DOI: 10.1016/j.cherd.2013.05.023.

[24] T. J. Goncalves, U. Arnold, P. N. Plessow, F. Studt, ACS Catal. 2017, 7 (5), 3615 3621. DOI: 10.1021/acscatal.7b00701.

[25] Z. Xue, H. Shang, Z. Zhang, C. Xiong, C. Lu, G. An, Energy Fuels 2017, 31 (1), 279 286. DOI: 10.1021/acs.energyfuels.6b02255.

[26] J.-O. Weidert, J. Burger, M. Renner, S. Blagov, H. Hasse, Ind. Eng. Chem. Res. 2017, 56 (2), 575 - 582. DOI: 10.1021/acs.iecr.6b03847.

[27] T. Grützner, H. Hasse, N. Lang, M. Siegert, E. Ströfer, Chemical Engineering Science 2007, 62 (18-20), 5613 - 5620. DOI: 10.1016/j.ces.2007.01.047.

[28] C. Arcoumanis, C. Bae, R. Crookes, E. Kinoshita, Fuel 2008, 87 (7), 1014 - 1030. DOI: 10.1016/j.fuel.2007.06.007.

[29] E. Schwab, M. Bender, DE102017201691A1, 2017.

[30] P. Haltenort, K. Hackbarth, D. Oestreich, L. Lautenschütz, U. Arnold, J. Sauer, Catalysis Communications 2018. DOI: 10.1016/j.catcom.2018.02.013.

[31] E. Ströfer, H. Schelling, H. Hasse, S. Blagov, US7999140 B2, 2006.

[32] R. L. Rowley, W. V. Wilding, J. L. Oscarson, Y. Yang, N. A. Zundel, T. E. Daubert, P. Danner, The DIPPR Information and Data Evaluation Manager for the Design Institute for Physical Properties, Version 12.2.0, AIChE 2018.

[33] N. Schmitz, A. Friebel, E. von Harbou, J. Burger, H. Hasse, Fluid Phase Equilibria 2016, 425, 127 - 135. DOI: 10.1016/j.fluid.2016.05.017.

[34] M. Albert, H. Hasse, C. Kuhnert, G. Maurer, J. Chem. Eng. Data 2005, 50 (4), 1218 1223. DOI: $10.1021 / \mathrm{je} 050015 \mathrm{i}$.

[35] A. T. Sundberg, P. Uusi-Kyyny, M. Pakkanen, V. Alopaeus, J. Chem. Eng. Data 2011, 56 (5), 2634 - 2640. DOI: 10.1021/je200140m.

[36] J. Burger, E. Ströfer, H. Hasse, Chem. Eng. Technol. 2016, 39 (2), 219 - 224. DOI: 10.1002/ceat.201500196.

[37] O. Ryll, S. Blagov, H. Hasse, Chemical Engineering Science 2012, 84, 315 - 332. DOI: 10.1016/j.ces.2012.08.018.

[38] M. Bortz, J. Burger, N. Asprion, S. Blagov, R. Böttcher, U. Nowak, A. Scheithauer, R. Welke, K.-H. Küfer, H. Hasse, Computers \& Chemical Engineering 2014, 60, 354 363. DOI: 10.1016/j.compchemeng.2013.09.015.

[39] S. Zeck, Chemie Ingenieur Technik 1990, 62 (9), 707 - 717. DOI: 10.1002/cite.330620904. 
Table 1: Standard enthalpy and entropy of formation, enthalpy and entropy of vaporization, enthalpy and entropy of fusion at $298.15 \mathrm{~K}$ and 1 bar used in the estimation of the present work. [32]

\begin{tabular}{|c|c|c|c|}
\hline Component $i$ & DME & TRX & MAL \\
\hline standard state & gas & solid & liquid \\
\hline$h_{i}^{\ominus} \quad / \mathrm{kJ} \mathrm{mol}^{-1}$ & -184.0 & -522.5 & -378.2 \\
\hline$\Delta h_{\mathrm{vap}, i}^{\theta} / \mathrm{kJ} \mathrm{mol}^{-1}$ & 18.63 & - & - \\
\hline$\Delta h_{\text {fus }, i}^{\theta} / \mathrm{kJ} \mathrm{mol}^{-1}$ & - & $14.62^{\mathrm{a}}$ & - \\
\hline$s_{i}^{\theta} \quad / \mathrm{J} \mathrm{mol}^{-1} \mathrm{~K}^{-1}$ & 266 & 129.1 & 244 \\
\hline$\Delta s_{\mathrm{vap}, i}^{\theta} / \mathrm{J} \mathrm{mol}^{-1} \mathrm{~K}^{-1}$ & 62.48 & - & - \\
\hline$\Delta s_{\text {fus }, i}^{\theta} / \mathrm{J} \mathrm{mol}^{-1} \mathrm{~K}^{-1}$ & - & 49.04 & - \\
\hline
\end{tabular}

Table 2: Parameters of the correlation of the liquid molar heat capacity $c_{p, i}^{\text {liq }}$ $\left(\left(c_{\mathrm{p}, i}^{\mathrm{liq}}(T) /\left(\mathrm{kJ} \mathrm{mol}^{-1} \mathrm{~K}^{-1}\right)\right)=A_{i}+B_{i} \cdot(T / \mathrm{K})+C_{i} \cdot(T / \mathrm{K})^{2}\right)[32]$

\begin{tabular}{c|ccc}
\hline Component $i$ & $A_{i}$ & $B_{i}$ & $C_{i}$ \\
\hline DME & 110100 & -157.47 & 0.51853 \\
\hline TRX & 94990 & -60.319 & 0.68234 \\
\hline MAL & 156280 & -189.65 & 0.69486 \\
\hline
\end{tabular}

Table 3: Parameters for the correlation of the equilibrium constants $K_{j}$ for the Reactions (1) to (7) according to Eq. (15).

\begin{tabular}{c|cc|c}
\hline Reaction & $a_{j}$ & $b_{j}$ & ref. \\
\hline 1 & 6.436 & -8197.8 & this work \\
\hline 2 & -4.341 & 3464.3 & this work \\
\hline 3 & -2.415 & 3029.6 & {$[12]$} \\
\hline 4 & -2.415 & 3029.6 & {$[12]$} \\
\hline 5 & -6.587 & 2195.1 & this work \\
\hline 6 & -0.2699 & 297 & {$[22]$} \\
\hline 7 & -0.2699 & 297 & {$[22]$} \\
\hline
\end{tabular}


Table 4: Specifications for the process given in Figure 2. The reactor temperature is always $353.15 \mathrm{~K}$ and the mass flow of the feed stream $10 \mathrm{~kg} \mathrm{~s}^{-1}$.

\begin{tabular}{c|ll}
\hline \multicolumn{1}{c}{ Model } & Process specification & Value \\
\hline \multirow{2}{*}{$\infty / \infty$ model } & $x_{1, \mathrm{DME}}$ & varied $/ \mathrm{g} \mathrm{g}^{-1}$ \\
\hline & $x_{1, \mathrm{DME}}$ & $0.284 \mathrm{~g} \mathrm{~g}^{-1}$ \\
\cline { 2 - 3 } & $T_{1}$ & $335.15 \mathrm{~K}$ \\
\cline { 2 - 3 } & $x_{7, \mathrm{OME}_{2}}+x_{7, \mathrm{TRX}}$ & $0.0005 \mathrm{~g} \mathrm{~g}^{-1}$ \\
\cline { 2 - 3 } & $x_{7, \mathrm{OME}_{26}}$ & $0.0095 \mathrm{~g} \mathrm{~g}^{-1}$ \\
\cline { 2 - 3 } & $T_{\mathrm{C} 1, \mathrm{cond}}$ & $313.15 \mathrm{~K}$ \\
\cline { 2 - 3 } & $p_{\mathrm{C} 2}$ & $50 \mathrm{mbar}$ \\
\cline { 2 - 3 } & $\dot{m}_{\mathrm{OME}_{3}, 4} / \dot{m}_{\mathrm{OME}_{3}, 3}$ & varied $/ \mathrm{g} \mathrm{g}^{-1}$ \\
\cline { 2 - 3 } & $\dot{m}_{\mathrm{OME}_{5}, 6} / \dot{m}_{\mathrm{OME}_{5}, 5}$ & varied $/ \mathrm{g} \mathrm{g} \mathrm{g}^{-1}$ \\
\hline
\end{tabular}

Table 5: Operating parameters for the columns $\mathrm{C} 1$ and $\mathrm{C} 2$ using the detailed process model. Heat flows are normalized by dividing by the mass flow of the product stream $\dot{m}_{7}$.

\begin{tabular}{l|l|l}
\hline Column & $\mathrm{C} 1$ & $\mathrm{C} 2$ \\
\hline$N$ & 13 & 22 \\
$N_{\text {feed }}$ & 12 & 15 \\
$\dot{m}_{\mathrm{OME}_{3}, 4} / \dot{m}_{\mathrm{OME}_{3}, 3}$ & $0.1141 \mathrm{~g} \mathrm{~g}^{-1}$ & - \\
$\dot{m}_{\mathrm{OME}_{5}, 6} / \dot{m}_{\mathrm{OME}_{5}, 5}$ & - & $0.003 \mathrm{~g} \mathrm{~g}^{-1}$ \\
$R$ & 0.015 & 1.367 \\
$\dot{Q}_{\text {cond }} / \dot{m}_{7}$ & $846 \mathrm{~kJ} \mathrm{~kg}^{-1}$ & $879 \mathrm{~kJ} \mathrm{~kg}^{-1}$ \\
$\dot{Q}_{\mathrm{reb}} / \dot{m}_{7}$ & $1749 \mathrm{~kJ} \mathrm{~kg}^{-1}$ & $121 \mathrm{~kJ} \mathrm{~kg}^{-1}$ \\
$p$ & $4.86 \mathrm{bar}$ & $0.05 \mathrm{bar}$ \\
\hline
\end{tabular}


Table 6: Stream table of the process given in Figure 2, simulated with the detailed process model. Mass flows are normalized with the mass flow of the product stream 7.

\begin{tabular}{lccccccc}
\hline Stream & 1 & 2 & 3 & 4 & 5 & 6 & 7 \\
\hline$T / \mathrm{K}$ & 335.15 & 363.73 & 353.15 & 313.15 & 572.48 & 476.43 & 360.60 \\
\hline$\dot{m} / \dot{m}_{7}$ & 1.000 & 4.043 & 4.043 & 1.660 & 2.383 & 1.383 & 1.000 \\
\hline \multicolumn{7}{c}{ mass fraction $/ \mathrm{g} \mathrm{g}^{-1}$} \\
FA & 0.0000 & 0.0004 & 0.0004 & 0.0010 & 0.0000 & 0.0000 & 0.0000 \\
DME & 0.2840 & 0.2175 & 0.1472 & 0.3586 & 0.0000 & 0.0000 & 0.0000 \\
TRX & 0.7160 & 0.2386 & 0.0615 & 0.1498 & 0.0000 & 0.0000 & 0.0000 \\
MAL & 0.0000 & 0.0918 & 0.0918 & 0.2236 & 0.0000 & 0.0000 & 0.0000 \\
OME $_{2}$ & 0.0000 & 0.0967 & 0.0968 & 0.2355 & 0.0002 & 0.0000 & 0.0005 \\
OME $_{3}$ & 0.0000 & 0.0107 & 0.0939 & 0.0261 & 0.1412 & 0.0000 & 0.3364 \\
OME $_{4}$ & 0.0000 & 0.0018 & 0.0867 & 0.0045 & 0.1440 & 0.0000 & 0.3430 \\
OME $_{5}$ & 0.0000 & 0.0006 & 0.0774 & 0.0008 & 0.1307 & 0.0007 & 0.3106 \\
OME $_{6}$ & 0.0000 & 0.0651 & 0.0675 & 0.0001 & 0.1144 & 0.1902 & 0.0095 \\
OME $_{7}$ & 0.0000 & 0.0578 & 0.0578 & 0.0000 & 0.0980 & 0.1689 & 0.0000 \\
OME $_{8}$ & 0.0000 & 0.0488 & 0.0488 & 0.0000 & 0.0828 & 0.1427 & 0.0000 \\
OME $_{9}$ & 0.0000 & 0.0408 & 0.0408 & 0.0000 & 0.0692 & 0.1192 & 0.0000 \\
OME $_{10}$ & 0.0000 & 0.0338 & 0.0338 & 0.0000 & 0.0573 & 0.0987 & 0.0000 \\
OME $_{11}$ & 0.0000 & 0.0277 & 0.0277 & 0.0000 & 0.0471 & 0.0811 & 0.0000 \\
OME $_{12}$ & 0.0000 & 0.0226 & 0.0226 & 0.0000 & 0.0384 & 0.0662 & 0.0000 \\
OME $_{13}$ & 0.0000 & 0.0184 & 0.0184 & 0.0000 & 0.0312 & 0.0538 & 0.0000 \\
OME $_{14}$ & 0.0000 & 0.0149 & 0.0149 & 0.0000 & 0.0252 & 0.0435 & 0.0000 \\
OME $_{215}$ & 0.0000 & 0.0120 & 0.0120 & 0.0000 & 0.0203 & 0.0350 & 0.0000 \\
\hline
\end{tabular}


Figure 1: Overview of different routes from syngas to OME. Reproduced with modifications from Burger [13].

Figure 2: Flowsheet of the OME production process from dimethyl ether and trioxane [31].

Figure 3: Molar equilibrium constants of the formation of methylal from formaldehyde and dimethyl ether $\left(K_{2}\right)$ and the constant for the formation of $\mathrm{OME}_{2}$ from methylal and formaldehyde $\left(K_{3}\right)$ in a logarithmic plot over the inverse temperature.

Figure 4: Pareto front for the objectives mass flow of recycle stream 6 and mass flow of recycle stream 4, normalized with the mass flow of stream 7 (product). The operating point $(X)$ is assumed to be a good compromise between the two objectives.

Figure 5: $N, Q$-curves showing the Trade-off between number of stages and reboiler duty for a) $\mathrm{C} 1$ and b) $\mathrm{C} 2$. $X$ : design point. -- : minimum reboiler duty. 


\section{Table of contents}

Poly(oxymethylene) dimethyl ethers are interesting clean synthetic fuels. They can be produced from syngas and metallurgical gases from steel production via several routes. Here, the route via dimethyl ether and trioxane is studied. The physicochemical properties are estimated and a process design is carried out for a preliminary assessment of the route. Here Figure TableofContents 